\title{
Acute Effects of 3,4-Methylenedioxymethamphetamine (MDMA) and $R(-)$ MDMA on Actigraphy-Based Daytime Activity and Sleep Parameters in Rhesus Monkeys
}

\author{
Laís F. Berro, $\mathrm{PhD}^{1,2}$, Hannah Shields ${ }^{1}$, Melis Odabas-Geldiay ${ }^{1}$, Barbara O. Rothbaum, PhD, \\ ABPP ${ }^{3}$, Monica L. Andersen, PhD $^{1,4}$, and Leonard L. Howell, PhD ${ }^{1,3,{ }^{*}}$ \\ ${ }^{1}$ Yerkes National Primate Research Center, Emory University, 954 Gatewood Road N.E., Atlanta, \\ GA, USA, 30329 \\ ${ }^{2}$ Department of Psychiatry and Human Behavior, University of Mississippi Medical Center, $2500 \mathrm{~N}$ \\ State St, Jackson, MS, USA 39216 \\ ${ }^{3}$ Department of Psychiatry and Behavioral Science, Yerkes National Primate Research Center, \\ Emory University, 954 Gatewood Road N.E., Atlanta, GA, USA, 30329 \\ ${ }^{4}$ Department of Psychobiology, Universidade Federal de São Paulo, R. Napoleão de Barros, 925, \\ 04021002 São Paulo, SP, Brazil
}

\section{Abstract}

3,4-Methylenedioxymethamphetamine (MDMA) affects monoaminergic pathways that play a critical role in sleep-wake cycles. Dopaminergic mechanisms are thought to mediate the sleepdisrupting effects of stimulant drugs. However, the mechanisms underlying the effects of MDMA on sleep-wake cycles and the effects of $R(-)$ MDMA, a stereoisomer that lacks dopaminergic activity, on sleep remain unknown. The aim of the present study was to investigate the effects of racemic MDMA and $R(-)$ MDMA on daytime activity and sleep-like parameters evaluated with actigraphy in adult rhesus macaques (Macaca mulatta, $\mathrm{n}=6$ ). Actiwatch monitors were attached to the monkeys' collars and actigraphy recording was conducted during baseline conditions and after the administration of acute intramuscular injections of saline (vehicle), racemic MDMA (0.3, 1.0 or $1.7 \mathrm{mg} / \mathrm{kg}$ ) or $R(-)$ MDMA ( $0.3,1.0$ or $1.7 \mathrm{mg} / \mathrm{kg}$ ) at $9 \mathrm{~h}$ or $16 \mathrm{~h}$ (3h prior to "lights off").

Morning treatments had no effects on sleep-like parameters. Racemic MDMA decreased general daytime activity during the $1^{\text {st }}$ hour after injection and increased daytime activity at 3 hours posttreatment. Although afternoon administration of racemic MDMA increased sleep latency, it improved other sleep parameters, decreasing wake time after sleep onset (WASO) and increasing sleep efficiency for subjects with low baseline sleep efficiency. Afternoon treatment with $R(-)$ MDMA improved sleep measures, increasing sleep efficiency and decreasing sleep latency and WASO, while having no effects on daytime activity. The stimulant and sleep-disrupting effects of

*Correspondence: Leonard L. Howell, Yerkes National Primate Research Center, Emory University, 954 Gatewood Road N.E., Atlanta, GA, USA, 30329, Phone: (+1)404-727-7786, Fax: (+1)404-727-1266, lhowell@emory.edu.

Disclosures

All authors contributed in a significant way to the manuscript and all authors have read and approved the final manuscript for publication.

The authors declare no conflicts of interest. 
racemic MDMA are likely mediated by dopaminergic and noradrenergic mechanisms, while serotonergic pathways appear to be involved in the sleep-promoting effects of MDMA.

\section{Keywords}

3, 4-Methylenedioxymethamphetamine; stereoisomer; sleep; actigraphy; rhesus monkeys

\section{Introduction}

Ecstasy is a commonly used recreational drug, with the most recent edition of the World Drug Report describing nearly 19.4 million global users (United Nations Office on Drugs and Crime, 2016). Racemic ( \pm )3,4-methylenedioxymethamphetamine (MDMA), the active component of ecstasy, is an amphetamine derivative that has stimulant, mood-enhancing, prosocial and hallucinogen-like effects (Shulgin, 1986; Harris et al., 2002; Pitts et al., 2017). Due to those effects, recent studies have investigated the therapeutic utility of racemic MDMA for the treatment of psychiatric disorders such as social anxiety, autism and posttraumatic stress disorder (PTSD), with encouraging results (Mithoefer et al., 2013, 2016; Amoroso and Workman, 2016; Danforth et al., 2016; Young et al., 2015, 2017; Pitts et al., 2017; Yazar-Klosinski and Mithoefer, 2017). However, the broad pharmacological actions of racemic MDMA translate not only into therapeutic efficacy, but also into the generation of adverse effects and abuse liability (Hardaway et al., 2016).

The broad effects of racemic MDMA are mediated mainly by serotonin neurotransmission, as it has high affinity for the serotonin transporter (SERT), causing significant increases in extracellular serotonin (Berger et al., 1992). However, the complexity of effects generated by racemic MDMA seems to be influenced by the differential effects of its stereoisomers. The psychomotor stimulant and dopamine-releasing effects of racemic MDMA have been attributed to $S(+)$ MDMA, while $R(-)$ MDMA has been shown to contribute to its hallucinogen effects through serotonergic mechanisms (Glennon et al., 1988; Baker et al., 1995; Murnane et al., 2009, 2010).

The stimulant nature of racemic MDMA and the putative role of serotonin in sleep (Rancillac, 2016) have prompted researchers to investigate the effects of racemic MDMA on sleep-wake patterns. Racemic MDMA-induced sleep disruption has been reported in current and former chronic MDMA users (Allen et al., 1993; Carhart-Harris et al., 2009; Taurah et al., 2014). Acute racemic MDMA administration has also been shown to increase wakefulness and disrupt objective sleep measures in rodents (Balogh et al., 2004), and to increase subject-rated levels of sleeplessness and restless sleep in humans (Baylen and Rosenberg, 2006; Huxster et al., 2006). In what seems to be the only study to date investigating the effects of acute MDMA on objective sleep measures in humans, a preliminary study with 7 MDMA-using participants showed altered sleep architecture after acute MDMA administration (Randall et al., 2009). Acute MDMA shortened sleep primarily by increasing sleep latency, also reducing slow wave sleep (SWS) and suppressing rapid eye movement (REM) sleep (Randall et al., 2009). However, no study to date has evaluated objective sleep-related effects of acute racemic MDMA in non-human primates or the effects 
of MDMA's stereoisomers on sleep. Because sleep architecture in rhesus monkeys strongly resembles that of humans, this is a unique animal model for human sleep (Daley et al., 2006). Importantly, studies have also shown that the effects of psychostimulant drugs on sleep are also similar in humans and rhesus monkeys (Ballard et al., 2015; Berro et al., 2017b).

The aim of the present study was to investigate the effects of racemic MDMA on daytime activity and sleep-like parameters evaluated with actigraphy in adult rhesus macaques. Based on the marked serotonergic effects of racemic MDMA, it has been suggested that serotonergic mechanisms mediate chronic MDMA-induced sleep disruption (for review, see Parrott, 2013). However, studies indicate that the sleep-disrupting effects of stimulant drugs seem to be mediated by dopaminergic mechanisms (Andersen et al., 2010; Murnane et al., 2013). Thus, in the present study we also investigated the effects of $R(-)$ MDMA, a stereoisomer that lacks dopaminergic activity (Murnane et al., 2010), on daytime activity and actigraphy-based sleep-like measures to shed light into the mechanisms underlying the effects of MDMA on sleep-wake cycles.

\section{Methods}

\section{Subjects}

Five adult female (RDn8, RNb7, RZs9, RVm8 and RKf9) and one adult male (RJ18) rhesus monkeys (Macaca mulatta) weighing $8-16 \mathrm{~kg}$, served as subjects for the studies. Animals were fitted with collars (Primate Products) prior to the initiation of the studies. Each subject was individually housed in stainless steel home cages and fed Purina monkey chow (Ralston Purina, St. Louis, MO), supplemented with fruit and vegetables daily. Water was continuously available in the colony. Environmental enrichment was provided on a regular basis. The colony was maintained at an ambient temperature of $22 \pm 2^{\circ} \mathrm{C}$ at $45-50 \%$ humidity, and the lights were set to a 12-h light/dark cycle (lights on at 7h; lights off at 19h). All subjects had a long history of exposure to psychostimulants (Andersen et al., 2013; Perez Diaz et al., 2017; Berro et al., 2016, 2017a,b,c). Subjects RZs9, RVm8, and RJ18 had at least 4 years of experience on methamphetamine self-administration prior to this study. Subject RDn8 had a previous history ( $\sim 3$ years) of cocaine self-administration, and together with subject RNb7 had a history of i.v. psychostimulant treatments (once a week, every other week, for approximately 5 years) during in vivo microdialysis studies. Subject RKf9 had a history of occasional (every other week) psychostimulant exposure during awake fMRI scans for the previous 3 years. All protocols and animal care and handling strictly followed the National Institutes of Health Guide for the Care and Use of Laboratory Animals ( $8^{\text {th }}$ edition, revised 2011) and the recommendations of the American Association for Accreditation of Laboratory Animal Care, and were approved by the Institutional Animal Care and Use Committee of Emory University.

\section{Drugs}

Racemic ( \pm ) MDMA and $R(-)$ MDMA $\mathrm{HCl}$ were supplied by the National Institute on Drug Abuse (Research Technology Branch, Research Triangle Park, NC, USA) and were 
dissolved in $0.9 \%$ sterile physiological saline and administered intramuscularly (i.m.). Drug doses were calculated and expressed as the salt form.

\section{Actigraphy-based daytime activity and sleep parameters}

Actiwatch sensors (Mini Mitter, Bend, OR, USA) were used to assess daytime and nighttime activity, as previously described (Andersen et al., 2010, 2013; Murnane et al., 2013). Briefly, the Actiwatch device consisted of an omni-directional sensor that is sensitive to motion (recorded as activity counts). The monitors were programmed to record the total piezoelectric voltage generated over the preceding $60 \mathrm{~s}$ (i.e. epoch length $=60 \mathrm{~s}$ ). The devices record the intensity, amount, and duration of movement in all 3 planes. Subjects had been adapted to wearing the activity monitors and trained to cooperate with the attachment of the sensor in their collars while seated in primate chairs (Primate Products). Daytime activity data generated activity counts/hour. Nighttime activity data generated the following sleeplike behavior parameters: sleep efficiency (i.e., the percentage of the dark phase spent sleeping); sleep latency (i.e., the time between "lights off" at 19h and the first sleep bout); wake time after sleep onset (WASO, i.e., the time spent awake from sleep onset to "lights on" at $7 \mathrm{~h}$ ). All parameters were calculated using the Actiware Sleep 3.4 software program (Mini-Mitter, Bend, OR, USA). Sleep measurements were automatically calculated from the underlying activity counts using a temporal smoothing algorithm on the basis that sleeping or wakefulness are continuous behaviors. The Actiware analysis software automatically inferred sleep-like parameters from activity counts during each 60-s epoch by comparing the sum of the activity counts in that epoch and neighboring epochs to a predefined criterion. The specific formula used is the sum of the activity in the epoch under evaluation, plus the activity in the epochs immediately before and after the epoch under evaluation times $1 / 5$, plus the activity in the epochs that occurred 2 epochs before and after the epoch under evaluation times $1 / 25$.

\section{Protocol design}

Before the beginning of drug treatments, Actiwatches were attached to the monkeys' collars and baseline sleep-like behavior and daytime activity were measured for 1 week. Actigraphy recording continued for the duration of the treatments. Each subject was administered an intramuscular injection of saline (vehicle), racemic MDMA $(0.3,1.0$ or $1.7 \mathrm{mg} / \mathrm{kg}$ ) or $R(-)$ MDMA $(0.3,1.0$ or $1.7 \mathrm{mg} / \mathrm{kg}$ ) at $9 \mathrm{~h}$ or $16 \mathrm{~h}$ (3h prior to the beginning of the dark period) on distinct days with at least 2 days between each treatment. The doses of racemic MDMA and $R(-)$ MDMA were chosen based on previous studies from our laboratory investigating the behavioral, endocrine and neurochemical effects of racemic MDMA and $R(-)$ MDMA in rhesus monkeys (Murnane et al., 2010; Fantegrossi et al., 2009; McClung et al., 2010; Murnane et al., 2012). A 1-week baseline period was given between sets of treatments (racemic MDMA or $R(-)$ MDMA, morning or afternoon). Except for subject RJ18, all other subjects were housed in the same housing room. All experiments were carried out contemporaneously and baseline sleep data were collected during the same week for all animals. During the treatment phase, the order of drug treatments, including vehicle treatments, and doses was randomized and counterbalanced across subjects, minimizing any potential influences of one subject's sleep alterations over others. 


\section{Data analysis}

Baseline data were combined across a 5 day span of time. Sleep data were analyzed using one-way repeated-measures (RM) analysis of variance (ANOVA) corrected for multiple comparisons using Dunnett's test. Daytime activity data were analyzed using two-way RM ANOVA (time and treatment factors) corrected for multiple comparisons using Dunnett's test. Correlational analyses were conducted using Pearson's Correlation. All graphical data presentations were created using Prism 5 (GraphPad Software), and all statistical tests were performed using PASW Statistics 18 (SPSS Statistics Software). Significance was accepted at an alpha of 0.05 .

\section{Results}

\section{Sleep-wake pattern}

Sleep-like measures-Sleep-like measures are presented as normalized data (percentage of baseline). Individual-subject baseline data are presented in Table 1. One-way RM ANOVA showed no significant differences between treatment conditions for sleep efficiency (SE), sleep latency (SL) or WASO when subjects were given morning $(9 \mathrm{~h})$ treatments with racemic MDMA (SE: $[F(3,12)=1.42, p>0.05]$, Figure 1A; $\operatorname{SL}:[F(3,12)=0.73, p>0.05]$, Figure 1B; WASO: $[\mathrm{F}(3,12)=0.761, \mathrm{p}>0.05]$, Figure 1C) or $R(-)$ MDMA $(\mathrm{SE}:[\mathrm{F}(3,12)=$ $0.98, p>0.05]$, Figure 1D; SL: $[\mathrm{F}(3,12)=0.42, \mathrm{p}>0.05]$, Figure 1E; WASO: $[\mathrm{F}(3,12)=1.05$, $\mathrm{p}>0.05]$, Figure 1F). One-way RM ANOVA corrected for multiple comparisons using Dunnett's test showed significant differences between treatment conditions for sleep efficiency (SE), sleep latency (SL) and WASO when subjects were given afternoon (16h) treatments with racemic MDMA (SE: $[\mathrm{F}(3,15)=2.45$, p>0.05], Figure 2A; SL: $[\mathrm{F}(3,15)=$ $6.65, \mathrm{p}<0.05]$, Figure 2B; WASO: [F(3,15) $=5.16, \mathrm{p}<0.05]$, Figure $2 \mathrm{C}$ ) or $R(-)$ MDMA (SE: $[F(3,15)=5.67, p<0.05]$, Figure 2D; SL: $[F(3,15)=6.11, p<0.05]$, Figure 2E; WASO:

$[F(3,15)=3.54, p<0.05]$, Figure $2 F)$. While having no significant effects on sleep efficiency (Figure 2A), afternoon treatment with racemic MDMA dose-dependently increased sleep latency (Figure 2B) and decreased WASO (Figure 2C). Afternoon treatment with $R(-)$ MDMA improved outcomes for all sleep-like measures, inducing a dose-dependent increase in sleep efficiency (Figure 2D), decrease in sleep latency (Figure 2E) and decrease in WASO (Figure 2F). Correlational analysis showed a negative correlation between baseline sleep efficiency and percent change in sleep efficiency after afternoon treatment with $1.7 \mathrm{mg} / \mathrm{kg}$ racemic MDMA $[r=-0.98, p<0.001]$, suggesting that the lower the subject's baseline sleep efficiency, the higher the change in sleep efficiency after racemic MDMA afternoon treatment. In fact, individual subject data show a dose-dependent increase in sleep efficiency after afternoon racemic MDMA for animals with low, but not high, baseline sleep efficiency (Figure 3A). A significant correlation was also observed for sleep efficiency after afternoon treatment with $1.7 \mathrm{mg} / \mathrm{kg} R(-)$ MDMA (Figure 5D) [r $=-0.99$, p<0.0001], with $R(-$ ) MDMA dose-dependently increasing sleep efficiency for all subjects (Figure 3D). No significant correlations were observed between baseline sleep latency or WASO and percent change in sleep parameters after afternoon treatments with $1.7 \mathrm{mg} / \mathrm{kg}$ racemic MDMA ( $[\mathrm{r}=$ $-0.52, \mathrm{p}>0.05]$ and $[\mathrm{r}=-0.58, \mathrm{p}>0.05]$, respectively) or $1.7 \mathrm{mg} / \mathrm{kg} R(-)$ MDMA ([r $=-0.27$, $\mathrm{p}>0.05]$ and $[\mathrm{r}=-0.58, \mathrm{p}>0.05]$, respectively). 
Daytime activity measures-Daytime activity measures (activity counts across the hours following racemic MDMA or $R(-)$ MDMA injections at 16h) are presented as normalized data (percentage of baseline). Individual-subject baseline data are presented on Table 1. Two-way RM ANOVA corrected for multiple comparisons using Dunnett's test showed a significant interaction effect between time (16h-19h) and treatment (vehicle vs racemic MDMA) on daytime activity after afternoon racemic MDMA treatment $[\mathrm{F}(6,24)=$ $3.87, \mathrm{p}<0.05]$. At the $1^{\text {st }}$ hour after injection $(16 \mathrm{~h}-17 \mathrm{~h})$, racemic MDMA dose-dependently decreased general home-cage activity, with $1.7 \mathrm{mg} / \mathrm{kg}$ racemic MDMA significantly decreasing daytime activity compared to vehicle (Figure 4A). While daytime activity returned to baseline levels at the $2^{\text {nd }}$ hour post-treatment, $1.7 \mathrm{mg} / \mathrm{kg}$ racemic MDMA significantly increased general home-cage activity at the $3^{\text {rd }}$ hour after injection $(18 \mathrm{~h}-19 \mathrm{~h})$ (Figure 4A). No significant differences were observed for daytime activity measures after afternoon treatment with $R(-)$ MDMA (Figure 4B), with two-way RM ANOVA showing no effect of time $[\mathrm{F}(2,8)=3.48, \mathrm{p}>0.05]$ or treatment $[\mathrm{F}(3,12)=0.4, \mathrm{p}>0.05]$. Analysis of the daytime activity on the days after nighttime MDMA treatments showed no significant differences compared to baseline (data not shown).

\section{Discussion}

In the present study, we investigated the effects of racemic and $R(-)$ MDMA on daytime activity and sleep-like behavior generated by actigraphy in adult rhesus monkeys. Morning treatment with either compound had no effects on sleep-like parameters. Treatment with racemic MDMA decreased general daytime activity during the $1^{\text {st }}$ hour after injection, while showing daytime stimulant effects at 3 hours post-treatment. In agreement with the daytime stimulant effects, afternoon treatment with racemic MDMA induced a marked dosedependent increase in sleep latency in all subjects, with no significant differences on sleep efficiency. Individual subject data as well as correlational analysis indicated, however, that racemic MDMA had differential effects on sleep efficiency depending on subjects' baseline sleep parameters, improving this sleep measure for subjects with low baseline sleep efficiency. Accordingly, a dose-dependent decrease in WASO was observed after afternoon racemic MDMA administration. Afternoon treatment with $R(-)$ MDMA improved sleep measures for all subjects, increasing sleep efficiency and decreasing sleep latency and WASO, having no effects on general home-cage daytime activity.

The biphasic effects of racemic MDMA on daytime activity observed in the present study had been previously reported in rhesus monkeys. Crean and colleagues (Crean et al., 2007) reported decreased daytime activity during the $1^{\text {st }}$ hour after racemic MDMA injection and increased general home-cage activity at 3 hours post-treatment. Similarly, a recent study from our group has shown decreased general daytime activity during the $1^{\text {st }}$ hour following racemic MDMA administration in squirrel monkeys (Pitts et al., 2017). Importantly, $R(-)$ MDMA, a stereoisomer that has no effects on dopamine release (Murnane et al., 2010), did not alter daytime activity at any time-point following drug administration, suggesting that the stimulant effects of racemic MDMA are likely due to its dopamine-releasing effects. However, the present findings suggest that, contrary to what is observed for other psychostimulant drugs such as amphetamine (Murnane et al., 2013) and methamphetamine (Berro et al., 2017a), the stimulant effects of racemic MDMA may take up to 2 hours to 
emerge. Racemic MDMA shows a lower dopamine to serotonin release profile compared to other psychostimulant compounds (Rothman et al., 2001), that could explain the unique effects of racemic MDMA on daytime activity.

Consistent with the daytime stimulant effects emerging at 3 hours post-treatment, afternoon treatment with racemic MDMA induced a marked dose-dependent increase in sleep latency. The present findings are in agreement with previous studies showing that increased sleep latency is the main sleep-related effect of acute racemic MDMA administration. The effects of MDMA on sleep architecture have been reported in rodents, showing increased wakefulness and decreased SWS and REM sleep time (Baylen and Rosenberg, 2006). A preliminary study in humans has also reported reduced SWS and REM sleep time after acute MDMA administration, with shortened sleep primarily due to increased sleep latency, when participants were given an 8-hour sleep opportunity (Randall et al., 2009).

Both in the studies with rodents (Balogh et al., 2004) and in the present study, racemic MDMA-induced delayed sleep onset was associated with increased general daytime activity, suggesting that the effects of racemic MDMA on sleep latency are associated with its daytime stimulant effects. Similar effects have been previously reported for other psychostimulant drugs, such as amphetamine (Murnane et al., 2013) and methamphetamine (Andersen et al., 2013; Berro et al., 2016, 2017a.b). Importantly, in the study by Crean and colleagues (Crean et al., 2007), as well as in other studies by the same group (Crean et al., 2006; Taffe et al., 2006; Von Huben et al., 2007), racemic MDMA has been shown to induce significant increases in body temperature in rhesus monkeys, an effect that can last for up to 4 hours (Taffe et al., 2005). Although the authors show that this effect was not coupled to MDMA-induced changes in daytime activity (Crean et al., 2007), circadian body temperature rhythms are a signaling pathway for the modulation of sleep and wakefulness (Van Someren, 2000). Changes in core body temperature have a major influence on sleep regulation and are known to affect the ability to initiate sleep (Romeijn et al., 2012). Thus, MDMA-induced hyperthermia could also contribute to the effects of racemic MDMA on sleep latency. Corroborating this hypothesis, a recent study has shown that $R(-)$ MDMA did not increase body temperature in rodents (Curry et al., 2018), which is in line with the lack of negative effects of $R(-)$ MDMA on sleep latency observed in the present study.

Because other psychostimulant drugs, such as methamphetamine, also induce hyperthermia in rhesus monkeys (Crean et al., 2007), the effects of those drugs on sleep latency could also be attributable to their effects on body temperature in addition to their stimulant effects. Although racemic MDMA and other amphetamine-type drugs exert similar effects on sleep latency, those drugs seem to exert distinct effects on other sleep parameters. In our previous studies, amphetamine and methamphetamine administration also impaired sleep by decreasing sleep efficiency and increasing sleep fragmentation (Murnane et al., 2013; Andersen et al., 2013, Berro et al., 2016, 2017a,b). While MDMA had no significant effects on sleep fragmentation (data not shown), it significantly decreased WASO, also increasing sleep efficiency in animals with low baseline sleep efficiency.

As previously mentioned, one of the main differences between MDMA and other psychostimulant drugs is that racemic MDMA acts predominantly as a serotonin releaser, 
showing a low dopamine to serotonin release profile (Rothman et al., 2001). Thus, we propose that the stimulant effects of MDMA on daytime activity are a consequence of the dopamine-releasing effects of racemic MDMA, and that increased dopamine levels impair sleep onset when racemic MDMA is given close to bedtime (afternoon treatments). However, racemic MDMA-induced serotonin release would also activate sleep-promoting serotonergic pathways and improve sleep measures after sleep onset and throughout the night. Because racemic MDMA also potentiates the activity of other neurotransmitter systems, it cannot be ruled out that other neural pathways might also be modulating its effects on daytime activity and sleep. For instance, racemic MDMA also increases brain levels of norepinephrine (NE), and evidence suggests that this effect is predominantly modulated by $S(+)$ MDMA (Steele et al. 1987; Verrico et al. 2007). NE is involved in the ascending arousal system, and high extracellular NE levels enhance neurotransmission along wake-promoting pathways (Mitchell and Weinshenker, 2010). Thus, in addition to changes in dopamine and serotonin neurotransmission, increased NE levels could also account for the increased sleep latency observed following racemic MDMA administration.

Regarding the effects of serotonin on sleep, previous studies in humans have shown that acute treatment with the serotonin releaser fenfluramine and the serotonin reuptake inhibitor citalopram had no effects on sleep efficiency, sleep latency or wake time after sleep onset in humans (Myers et al., 1993; Neckelmann et al., 1996). However, changes in sleep architecture were observed after the administration of both compounds, including decreased percentage of time spent in slow wave sleep and changes on sleep power spectral parameters, with citalopram also decreasing percentage of time spent in REM sleep (Myers et al., 1993; Neckelmann et al., 1996). Those findings suggest that MDMA and $R(-)$ MDMA have a unique pharmacological profile that engenders sleep-inducing effects, but also emphasize the importance of further studies investigating the effects of MDMA and $R(-)$ MDMA on sleep architecture. The same study by Neckelmann and colleagues (1996) also showed that the effects of chronic treatment with citalopram on sleep parameters were different from those of acute citalopram administration, with more prominent changes in sleep architecture after chronic treatment. Because the chronic use of sedative-hypnotics is also known to induce tolerance (Santos and Olmedo, 2017), the investigation of the effects of acute doses is a limitation of the present study, and future studies investigating the effects of chronic MDMA and $R(-)$ MDMA on sleep are warranted.

Several studies have investigated the role of serotonin in the regulation of sleep-wake cycles, and yet the serotonergic pathways regulating sleep remain incompletely understood. Studies suggest that serotonin can have both an inhibitory and an excitatory effect in the ventrolateral preoptic nucleus (VLPO), the main sleep center in the brain, depending on the type of neuron that is being targeted (Rancillac, 2016). Importantly, serotonin 5- $\mathrm{HT}_{2 \mathrm{~A}}$ and 5$\mathrm{HT}_{2 \mathrm{C}}$ receptors seem to be the most frequent serotonin receptors in VLPO neurons (Sangare et al., 2016), and studies suggest that 5- $\mathrm{HT}_{2 \mathrm{~A}}$ receptor antagonists and $5-\mathrm{HT}_{2 \mathrm{C}}$ receptor agonists have sedative effects (Adam and Oswald, 1989; Landolt et al., 1999; Rosenberg et al., 2008; Morairty et al., 2008; Monti, 2011; Sangare et al., 2016). In fact, we have previously shown that antagonism of $5-\mathrm{HT}_{2 \mathrm{~A}}$ receptors as well as activation of $5-\mathrm{HT}_{2 \mathrm{C}}$ receptors decrease the sleep-disrupting effects of amphetamine-type stimulants in rhesus monkeys (Murnane et al., 2013; Perez Diaz et al., 2017). Thus, the sleep-promoting effects 
of racemic MDMA appear to be regulated by serotonergic pathways. By acting exclusively through serotonergic mechanisms, $R(-)$ MDMA would be expected to have sleep-promoting effects without the detrimental effects on daytime activity and on sleep latency observed with racemic MDMA. Furthermore, $R(-)$ MDMA has high affinity for 5- $\mathrm{HT}_{2}$ receptors (Lyon et al., 1986), that could contribute to the sleep-inducing effects observed in the present study after $R(-)$ MDMA afternoon administration.

The half-life of intravenous MDMA in rhesus monkeys is approximately $90 \mathrm{~min}$, reaching maximum plasma concentration at 5 min after injection (Banks et al., 2007). Accordingly, serotonin and prolactin levels induced by racemic MDMA return to baseline levels $90 \mathrm{~min}$ post injection (Murnane et al., 2012). Its metabolites, on the other hand, are still detected in the plasma for at least 4 hours after drug administration (Banks et al., 2007), suggesting that the effects of racemic MDMA on sleep observed in the present study could be attributed to its metabolites. Regarding $R(-)$ MDMA, to the best of our knowledge no studies to date have investigated its pharmacokinetics in rhesus monkeys. We have previously shown that serotonin and prolactin levels induced by $R(-)$ MDMA return to baseline levels at $60 \mathrm{~min}$ after injection (Murnane et al., 2012), indicating that the half-life of $R(-)$ MDMA could be shorter than that of racemic MDMA. However, studies in rodents (Fitzgerald et al., 1990) and humans (Fallon et al., 1999) have reported that the elimination half-life of $R(-)$ MDMA is significantly longer than that of the $S(+)$ enantiomer. Further studies are warranted to determine the pharmacokinetic profile of $R(-)$ MDMA in rhesus monkeys and the role $R(-)$ MDMA and racemic MDMA metabolites on the effects of MDMA on sleep

Due to its mood-enhancing and prosocial effects, recent studies have investigated the therapeutic utility of racemic MDMA for the treatment of psychiatric disorders such as social anxiety, autism and post-traumatic stress disorder (PTSD), with encouraging results (Mithoefer et al., 2013, 2016; Amoroso and Workman, 2016; Danforth et al., 2016; Young et al., 2015, 2017; Pitts et al., 2017; Yazar-Klosinski and Mithoefer, 2017). The broad pharmacological actions of racemic MDMA, however, translate not only into therapeutic efficacy, but also into the generation of adverse effects and abuse liability. Although it has never been studied in humans, racemic MDMA seems to have significant abuse potential (Hardaway et al., 2016), being self-administered by rodents (Schenk et al., 2016; van de Wetering and Schenk, 2017) and nonhuman primates (Wang and Woolverton, 2007). In addition, in the present study afternoon treatment with racemic MDMA induced stimulant effects and delayed sleep onset. Of importance for the treatment of PTSD, MDMA has been used in association with fear extinction (de Kleine et al., 2013; Young et al., 2015, 2017; Amoroso and Workman, 2016), a learning strategy that requires appropriate memory consolidation, with compelling evidence suggesting that sleep actively supports long-lasting memory formation (Melo and Ehrlich, 2016; Feld and Born, 2017). Thus, the balance between benefit and risk is one of the major challenges for the clinical use of racemic MDMA.

Our findings show that morning treatment with racemic or $R(-)$ MDMA had no effects on sleep-like parameters, suggesting that adverse side effects such as sleep impairment can be prevented by modulating the time of the day racemic MDMA is administered. The present study also provides relevant insights into clinical practice by showing that $R(-)$ MDMA 
improved sleep measures in rhesus monkeys without exerting stimulant effects on daytime activity. Thus, our findings suggest that $R(-)$ MDMA could have therapeutic potential without inducing adverse effects, corroborating previous findings in rodents showing that $R(-)$ MDMA has therapeutic effects in models of fear memory extinction and social interaction without exerting stimulant, thermogenic, and neurotoxic effects (Pitts et al., 2017; Curry et al., 2018). Although $R(-)$ MDMA self-administration has been reported in rhesus monkeys (Fantegrossi, 2008), opposing evidence suggests that the reinforcing effectiveness of racemic MDMA seems to derive primarily from $S(+)$ MDMA (Wang and Woolverton, 2007). For instance, racemic and $S(+)$, but not $R(-)$, MDMA were effective in inducing reinstatement of extinguished amphetamine self-administration (McClung et al., 2010). Further studies are warranted to determine the abuse liability as well as the therapeutic utility of $R(-)$ MDMA in humans. As previously mentioned, a limitation of the present study was the lack of evaluation of electrophysiological parameters of sleep, and future studies are needed to investigate the effects of racemic MDMA and $R(-)$ MDMA on sleep architecture. In addition to the potential applicability for the treatment of psychiatric disorders, our findings suggest that $R(-)$ MDMA could be useful for the treatment of sleep impairment in the context of mood and anxiety disorders as well as PTSD.

\section{Acknowledgments}

This research was supported by USPHS Grants DA10344 (LLH), DA031246 (LLH) and ODP51OD11132 (Yerkes), AFIP and FAPESP Grant 2015/25482-3 (LFB). The funding sources had no other role other than financial support.

The authors thank Juliet Brown for her excellent assistance with the experiments.

\section{References}

Adam K, Oswald I. Effects of repeated ritanserin on middle-aged poor sleepers. Psychopharmacology. 1989; 99:219-21. [PubMed: 2508157]

Allen RP, McCann UD, Ricaurte GA. Persistent effects of (+/-) 3,4-methylenedioxymethamphetamine (MDMA, “ecstasy”) on human sleep. Sleep. 1993; 16:560-564. [PubMed: 7901886]

Amoroso T, Workman M. Treating posttraumatic stress disorder with MDMA-assisted psychotherapy: A preliminary meta-analysis and comparison to prolonged exposure therapy. Journal of Psychopharmacology. 2016; 30:595-600. [PubMed: 27118529]

Andersen ML, Diaz MP, Murnane KS, Howell LL. Effects of methamphetamine self-administration on actigraphy-based sleep parameters in rhesus monkeys. Psychopharmacology. 2013; 227:101-7. [PubMed: 23263461]

Andersen ML, Kessler E, Murnane KS, McClung JC, Tufik S, Howell LL. Dopamine transporterrelated effects of modafinil in rhesus monkeys. Psychopharmacology. 2010; 210:439-48. [PubMed: 20386883]

Baker LE, Broadbent J, Michael EK, Matthews PK, Metosh CA, Saunders RB, West WB, Appel JB. Assessment of the discriminative stimulus effects of the optical isomers of ecstasy $(3,4-$ methylenedioxymethamphetamine; MDMA). Behavioural Pharmacology. 1995; 6:263-275. [PubMed: 11224335]

Ballard ME, Weafer J, Gallo DA, de Wit H. Effects of acute methamphetamine on emotional memory formation in humans: encoding vs consolidation. PLoS One. 2015; 10:e0117062. [PubMed: 25679982]

Balogh B, Molnar E, Jakus R, Quate L, Olverman HJ, Kelly PA, Kantor S, Bagdy G. Effects of a single dose of 3,4-methylenedioxymethamphetamine on circadian patterns, motor activity and sleep in drug-naive rats and rats previously exposed to MDMA. Psychopharmacology. 2004; 173:296309. [PubMed: 15083265] 
Banks ML, Sprague JE, Kisor DF, Czoty PW, Nichols DE, Nader MA. Ambient temperature effects on 3,4-methylenedioxymethamphetamine-induced thermodysregulation and pharmacokinetics in male monkeys. Drug Metabolism and Disposition. 2007; 35:1840-5. [PubMed: 17640955]

Baylen CA, Rosenberg H. A review of the acute subjective effects of MDMA/ecstasy. Addiction. 2006; 101:933-47. [PubMed: 16771886]

Berger UV, Gu XF, Azmitia EC. The substituted amphetamines 3,4-methylenedioxymethamphetamine, methamphetamine, $\mathrm{p}$-chloroamphetamine and fenfluramine induce 5-hydroxytryptamine release via a common mechanism blocked by fluoxetine and cocaine. European Journal of Pharmacology. 1992; 215:153-60. [PubMed: 1356787]

Berro LF, Andersen ML, Howell LL. Assessment of tolerance to the effects of methamphetamine on daytime and nighttime activity evaluated with actigraphy in rhesus monkeys. Psychopharmacology. 2017b; 234:2277-2287. [PubMed: 28589263]

Berro LF, Andersen ML, Tufik S, Howell LL. Actigraphy-based sleep parameters during the reinstatement of methamphetamine self-administration in rhesus monkeys. Experimental and Clinical Psychopharmacology. 2016; 24:142-6. [PubMed: 26882419]

Berro LF, Andersen ML, Tufik S, Howell LL. GABAA receptor positive allosteric modulators modify the abuse-related behavioral and neurochemical effects of methamphetamine in rhesus monkeys. Neuropharmacology. 2017a; 123:299-309. [PubMed: 28495376]

Berro LF, Perez Diaz M, Maltbie E, Howell LL. Effects of the serotonin 2C receptor agonist WAY 163909 on the abuse-related effects and mesolimbic dopamine neurochemistry induced by abused stimulants in rhesus monkeys. Psychopharmacology. 2017c [in press].

Carhart-Harris RL, Nutt DJ, Munafò M, Wilson SJ. Current and former ecstasy users report different sleep to matched controls: a web-based questionnaire study. Journal of Psychopharmacology. 2009; 23:249-257. [PubMed: 18562419]

Crean RD, Davis SA, Taffe MA. Oral Administration of ( \pm 3),4-Methylenedioxymethamphetamine and (+)Methamphetamine Alters Temperature and Activity in Rhesus Macaques. Pharmacology, Biochemistry \& Behavior. 2007; 87:11-19.

Crean RD, Davis SA, Von Huben SN, Lay CC, Katner SN, Taffe MA. Effects of (+/-)3,4methylenedioxymethamphetamine, (+/-)3,4-methylenedioxyamphetamine and methamphetamine on temperature and activity in rhesus macaques. Neuroscience. 2006; 142:515-25. [PubMed: 16876329]

Curry DW, Young MB, Tran AN, Daoud GE, Howell LL. Separating the agony from ecstasy: R(-)-3,4methylenedioxymethamphetamine has prosocial and therapeutic-like effects without signs of neurotoxicity in mice. Neuropharmacology. 2018; 128:196-206. [PubMed: 28993129]

Daley JT, Turner RS, Freeman A, Bliwise DL, Rye DB. Prolonged assessment of sleep and daytime sleepiness in unrestrained Macaca mulatta. Sleep. 2006; 29:221-31. [PubMed: 16494090]

Danforth AL, Struble CM, Yazar-Klosinski B, Grob CS. MDMA-assisted therapy: A new treatment model for social anxiety in autistic adults. Progress in Neuro-psychopharmacology \& Biological Psychiatry. 2016; 64:237-49. [PubMed: 25818246]

de Kleine RA, Rothbaum BO, van Minnen A. Pharmacological enhancement of exposure-based treatment in PTSD: a qualitative review. European Journal of Psychotraumatology. 2013:4.

Fallon JK, Kicman AT, Henry JA, Milligan PJ, Cowan DA, Hutt AJ. Stereospecific analysis and enantiomeric disposition of 3, 4-methylenedioxymethamphetamine (Ecstasy) in humans. Clinical Chemistry. 1999; 45:1058-69. [PubMed: 10388483]

Fantegrossi WE. In vivo pharmacology of MDMA and its enantiomers in rhesus monkeys. Experimental and Clinical Psychopharmacology. 2008; 16:1-12. [PubMed: 18266547]

Fantegrossi WE, Bauzo RM, Manvich DM, Morales JC, Votaw JR, Goodman MM, Howell LL. Role of dopamine transporters in the behavioral effects of 3,4-methylenedioxymethamphetamine (MDMA) in nonhuman primates. Psychopharmacology. 2009; 205:337-47. [PubMed: 19421742]

Feld GB, Born J. Sculpting memory during sleep: concurrent consolidation and forgetting. Current Opinion in Neurobiology. 2017; 44:20-27. [PubMed: 28278432]

Fitzgerald RL, Blanke RV, Poklis A. Stereoselective pharmacokinetics of 3,4methylenedioxymethamphetamine in the rat. Chirality. 1990; 2:241-8. [PubMed: 2083146] 
Glennon RA, Yousif M, Patrick G. Stimulus properties of 1-(3,4-methylenedioxyphenyl)-2aminopropane (MDA) analogs. Pharmacology, Biochemistry \& Behavior. 1988; 29:443-9.

Hardaway R, Schweitzer J, Suzuki J. Hallucinogen Use Disorders. Child and Adolescent Psychiatric Clinics of North America. 2016; 25:489-96. [PubMed: 27338969]

Harris DS, Baggott M, Mendelson JH, Mendelson JE, Jones RT. Subjective and hormonal effects of 3,4-methylenedioxymethamphetamine (MDMA) in humans. Psychopharmacology. 2002; 162:396-405. [PubMed: 12172693]

Huxster JK, Pirona A, Morgan MJ. The sub-acute effects of recreational ecstasy (MDMA) use: a controlled study in humans. Journal of Psychopharmacology. 2006; 20:281-90. [PubMed: 16510486]

Landolt HP, Meier V, Burgess HJ. Serotonin-2 receptors and human sleep: effect of a selective antagonist on EEG power spectra. Neuropsychopharmacology. 1999; 21:455-66. [PubMed: 10457543]

Lyon RA, Glennon RA, Titeler M. 3,4-Methylenedioxymethamphetamine (MDMA): stereoselective interactions at brain 5-HT1 and 5-HT2 receptors. Psychopharmacology. 1986; 88:525-6. [PubMed: 2871581]

McClung J, Fantegrossi W, Howell LL. Reinstatement of extinguished amphetamine selfadministration by 3,4-methylenedioxymethamphetamine (MDMA) and its enantiomers in rhesus monkeys. Psychopharmacology. 2010; 210:75-83. [PubMed: 20309529]

Melo I, Ehrlich I. Sleep supports cued fear extinction memory consolidation independent of circadian phase. Neurobiology of Learning and Memory. 2016; 132:9-17. [PubMed: 27109918]

Mitchell HA, Weinshenker D. Good night and good luck: norepinephrine in sleep pharmacology. Biochemical Pharmacology. 2010; 79:801-9. [PubMed: 19833104]

Mithoefer MC, Grob CS, Brewerton TD. Novel psychopharmacological therapies for psychiatric disorders: psilocybin and MDMA. Lancet Psychiatry. 2016; 3:481-8. [PubMed: 27067625]

Mithoefer MC, Wagner MT, Mithoefer AT, Jerome L, Martin SF, Yazar-Klosinski B, Michel Y, Brewerton TD, Doblin R. Durability of improvement in post-traumatic stress disorder symptoms and absence of harmful effects or drug dependency after 3,4-methylenedioxymethamphetamineassisted psychotherapy: a prospective long-term follow-up study. Journal of Psychopharmacology. 2013; 27:28-39. [PubMed: 23172889]

Monti JM. Serotonin control of sleep-wake behavior. Sleep Medicine Review. 15:269-81.

Morairty SR, Hedley L, Flores J. Selective 5HT2A and 5HT6 receptor antagonists promote sleep in rats. Sleep. 2008; 31:34-44. [PubMed: 18220076]

Murnane KS, Fantegrossi WE, Godfrey JR, Banks ML, Howell LL. Endocrine and neurochemical effects of 3,4-methylenedioxymethamphetamine and its stereoisomers in rhesus monkeys. Journal of Pharmacology and Experimental Therapeutics. 2010; 334:642-50. [PubMed: 20466795]

Murnane KS, Kimmel HL, Rice KC, Howell LL. The neuropharmacology of prolactin secretion elicited by 3,4-methylenedioxymethamphetamine ("ecstasy"): a concurrent microdialysis and plasma analysis study. Hormones and Behavior. 2012; 61:181-90. [PubMed: 22197270]

Murnane KS, Murai N, Howell LL, Fantegrossi WE. Discriminative stimulus effects of psychostimulants and hallucinogens in S(+)-3,4-methylenedioxymethamphetamine (MDMA) and R(-)-MDMA trained mice. Journal of Pharmacology and Experimental Therapeutics. 2009; 331:717-23. [PubMed: 19684254]

Murnane KS, Winschel J, Schmidt KT, Stewart LM, Rose SJ, Cheng K, Rice KC, Howell LL. Serotonin $2 \mathrm{~A}$ receptors differentially contribute to abuse-related effects of cocaine and cocaineinduced nigrostriatal and mesolimbic dopamine overflow in nonhuman primates. The Journal of Neuroscience. 2013; 33:13367-74. [PubMed: 23946394]

Myers JE, Buysse DJ, Thase ME, Perel J, Miewald JM, Cooper TB, Kupfer DJ, Mann JJ. The effects of fenfluramine on sleep and prolactin in depressed inpatients: a comparison of potential indices of brain serotonergic responsivity. Biological Psychiatry. 1993; 34:753-8. [PubMed: 8292678]

Neckelmann D, Bjorvatn B, Bjørkum AA, Ursin R. Citalopram: differential sleep/wake and EEG power spectrum effects after single dose and chronic administration. Behavioural Brain Research. 1996; 79:183-92. [PubMed: 8883829] 
Parrott AC. MDMA, serotonergic neurotoxicity, and the diverse functional deficits of recreational 'Ecstasy' users. Neuroscience \& Biobehavioral Reviews. 2013; 37:1466-84. [PubMed: 23660456]

Perez Diaz M, Andersen ML, Rice KC, Howell LL. Effects of a Serotonin 2C Agonist and a A Antagonist on Actigraphy-Based Sleep Parameters Disrupted by Methamphetamine SelfAdministration in Rhesus Monkeys. Neuropsychopharmacology. 2017; 42:1531-1538. [PubMed: 27986974]

Pitts EG, Curry DW, Hampshire KN, Young MB, Howell LL. ( \pm )-MDMA and its enantiomers: potential therapeutic advantages of R(-)-MDMA. Psychopharmacology. 2017 [in press].

Pitts EG, Minerva AR, Chandler EB, Kohn JN, Logun MT, Sulima A, Rice KC, Howell LL. 3,4Methylenedioxymethamphetamine Increases Affiliative Behaviors in Squirrel Monkeys in a Serotonin 2A Receptor-Dependent Manner. Neuropsychopharmacology. 2017; 42:1962-1971. [PubMed: 28425496]

Rancillac A. Serotonin and sleep-promoting neurons. Oncotarget. 2016; 7:78222-78223. [PubMed: 27861160]

Randall S, Johanson CE, Tancer M, Roehrs T. Effects of acute 3,4-methylenedioxymethamphetamine on sleep and daytime sleepiness in MDMA users: a preliminary study. Sleep. 2009; 32:513-9.

Romeijn N, Raymann RJ, Møst E, Te Lindert B, Van Der Meijden WP, Fronczek R, Gomez-Herrero G, Van Someren EJ. Sleep, vigilance, and thermosensitivity. Pflugers Archiv: European Journal of Physiology. 2012; 463:169-76. [PubMed: 22048563]

Rosenberg R, Seiden DJ, Hull S. APD125, a selective serotonin 5-HT(2A) receptor inverse agonist, significantly improves sleep maintenance in primary insomnia. Sleep. 2008; 31:1663-71. [PubMed: 19090322]

Rothman RB, Baumann MH, Dersch CM, Romero DV, Rice KC, Carroll FI, Partilla JS. Amphetamine-type central nervous system stimulants release norepinephrine more potently than they release dopamine and serotonin. Synapse. 2001; 39:32-41. [PubMed: 11071707]

Sangare A, Dubourget R, Geoffroy H, Gallopin T, Rancillac A. Serotonin differentially modulates excitatory and inhibitory synaptic inputs to putative sleep-promoting neurons of the ventrolateral preoptic nucleus. Neuropharmacology. 2016; 109:29-40. [PubMed: 27238836]

Santos C, Olmedo RE. Sedative-Hypnotic Drug Withdrawal Syndrome: Recognition And Treatment. Emergency Medicine Practice. 2017; 19:1-20.

Schenk S, Foote J, Aronsen D, Bukholt N, Highgate Q, Van de Wetering R, Webster J. Serotonin antagonists fail to alter MDMA self-administration in rats. Pharmacology, Biochemistry \& Behavior. 2016; 148:38-45.

Shulgin AT. The background and chemistry of MDMA. Journal of Psychoactive Drugs. 1986; 18:291304. [PubMed: 2880943]

Steele TD, Nichols DE, Yim GKW. Stereochemical effect S and related amphetamine derivatives on inhibition of uptake of $[3 \mathrm{H}]$ monoamines synaptosomes from different regions into of rat brain. Biochemical Pharmacology. 1987; 36:2297-2303. [PubMed: 2886126]

Taffe MA, Lay CC, Von Huben SN, Davis SA, Crean RD, Katner SN. Hyperthermia induced by 3,4methylenedioxymethamphetamine in unrestrained rhesus monkeys. Drug and Alcohol Dependence. 2006; 82:276-81. [PubMed: 16289931]

Taurah L, Chandler C, Sanders G. Depression, impulsiveness, sleep, and memory in past and present polydrug users of 3,4-methylenedioxymethamphetamine (MDMA, ecstasy). Psychopharmacology. 2014; 231:737-51. [PubMed: 24114426]

United Nations Office on Drugs and Crime (UNODC). World Drug Report. United Nations publication; 2016. Sales No. E.16.XI.7

van de Wetering R, Schenk S. Repeated MDMA administration increases MDMA-produced locomotor activity and facilitates the acquisition of MDMA self-administration: role of dopamine D2 receptor mechanisms. Psychopharmacology. 2017; 234:1155-1164. [PubMed: 28188355]

Van Someren EJ. More than a marker: interaction between the circadian regulation of temperature and sleep, age-related changes, and treatment possibilities. Chronobiology International. 2000; 17:313-354. [PubMed: 10841209]

Exp Clin Psychopharmacol. Author manuscript; available in PMC 2019 August 01. 
Verrico CD, Miller GM, Madras BK. MDMA (ecstasy) and human dopamine, norepinephrine, and serotonin transporters: implications for MDMA-induced neurotoxicity and treatment. Psychopharmacology. 2007; 189:489-503. [PubMed: 16220332]

Vollenweider FX, Liechti ME, Gamma A, Greer G, Geyer M. Acute psychological and neurophysiological effects of MDMA in humans. Journal of Psychoactive Drugs. 2002; 34:17184. [PubMed: 12691207]

Von Huben SN, Lay CC, Crean RD, Davis SA, Katner SN, Taffe MA. Impact of ambient temperature on hyperthermia induced by (+/-)3,4-methylenedioxymethamphetamine in rhesus macaques. Neuropsychopharmacology. 2007; 32:673-81. [PubMed: 16641942]

Wang Z, Woolverton WL. Estimating the relative reinforcing strength of (+/-)-3,4methylenedioxymethamphetamine (MDMA) and its isomers in rhesus monkeys: comparison to (+)-methamphetamine. Psychopharmacology. 2007; 189:483-8. [PubMed: 17063335]

Yazar-Klosinski BB, Mithoefer MC. Potential Psychiatric Uses for MDMA. Clinical Pharmacology and Therapeutics. 2017; 101:194-196. [PubMed: 27859039]

Young MB, Andero R, Ressler KJ, Howell LL. 3,4-Methylenedioxymethamphetamine facilitates fear extinction learning. Translational Psychiatry. 2015; 5:e634. [PubMed: 26371762]

Young MB, Norrholm SD, Khoury LM, Jovanovic T, Rauch SAM, Reiff CM, Dunlop BW, Rothbaum BO, Howell LL. Inhibition of serotonin transporters disrupts the enhancement of fear memory extinction by 3,4-methylenedioxymethamphetamine (MDMA). Psychopharmacology. 2017; 234:2883-2895. [PubMed: 28741031] 


\section{Public Significance Statements}

Using actigraphy, this is the first study to investigate acute MDMA and $R(-)$ MDMA effects on sleep in rhesus monkeys, a unique translational nonhuman primate model. We show that MDMA-induced increase in sleep latency can be prevented by modulating the time of the day MDMA is administered, and that $R(-)$ MDMA improved sleep without exerting stimulant effects. Further studies are warranted to determine the abuse liability and the therapeutic utility of $R(-)$ MDMA in humans for the treatment of sleep impairment in the context of psychiatric disorders.

Exp Clin Psychopharmacol. Author manuscript; available in PMC 2019 August 01. 


\section{Racemic MDMA Morning Treatments}
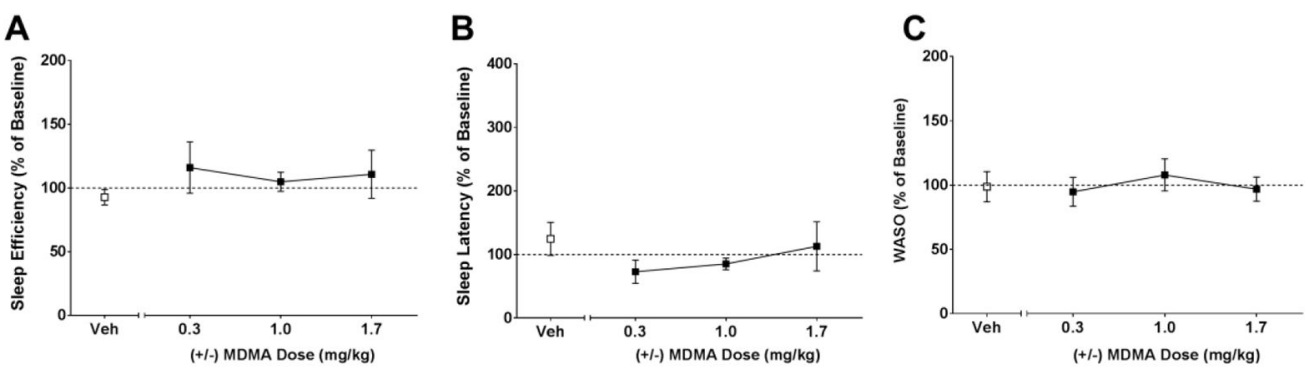

\section{$R(-)$ MDMA Morning Treatments}
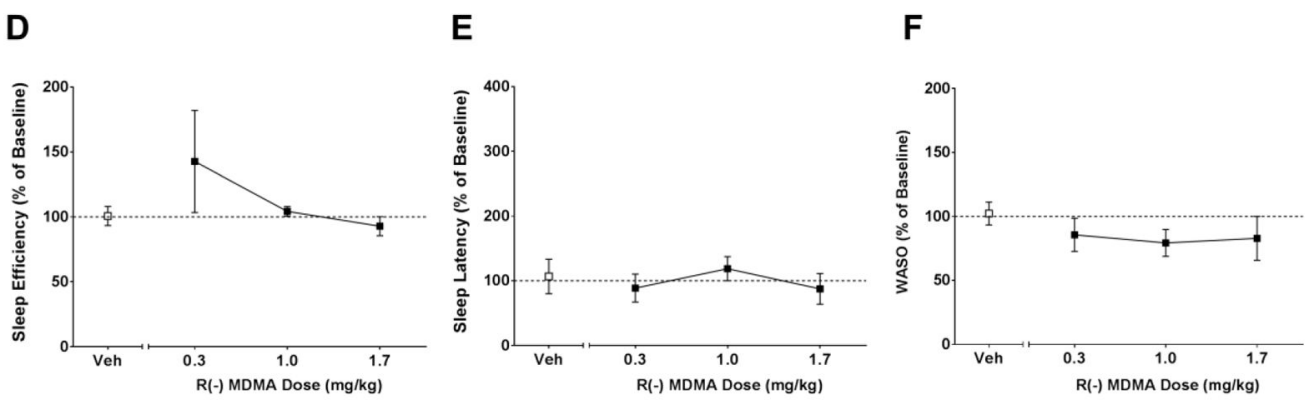

Figure 1.

$(A, D)$ Sleep efficiency, $(B, E)$ sleep latency and $(\mathrm{C}, \mathrm{F})$ wake time after sleep onset (WASO) in the nights after morning (9h) vehicle (Veh), racemic MDMA (0.3, 1.0 and $1.7 \mathrm{mg} / \mathrm{kg}$, i.m., upper panel) or R(-) MDMA (0.3, 1.0 and $1.7 \mathrm{mg} / \mathrm{kg}$, i.m., bottom panel) administrations (N $=5)$. Sleep-like measures are presented as normalized data (percentage of baseline). Data are expressed as mean \pm SEM. Dotted lines represent baseline sleep parameters (100\%).

Exp Clin Psychopharmacol. Author manuscript; available in PMC 2019 August 01. 


\section{Racemic MDMA Afternoon Treatments}
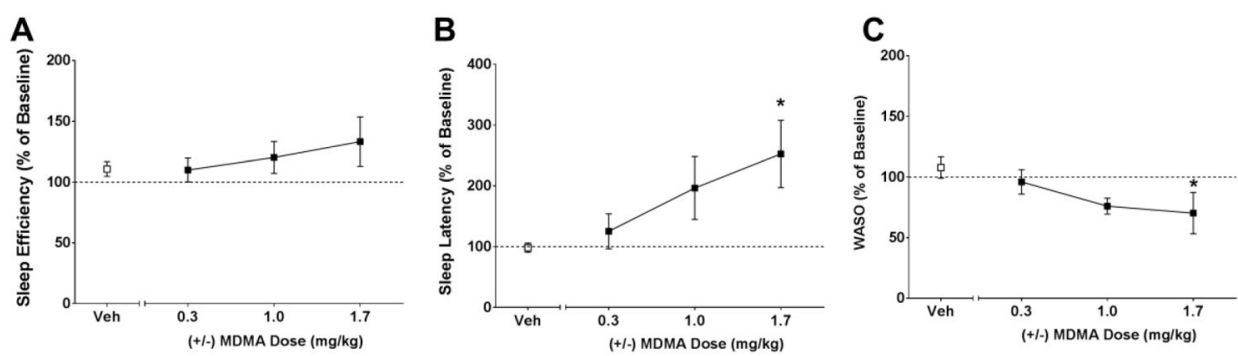

\section{$R(-)$ MDMA Afternoon Treatments}

D

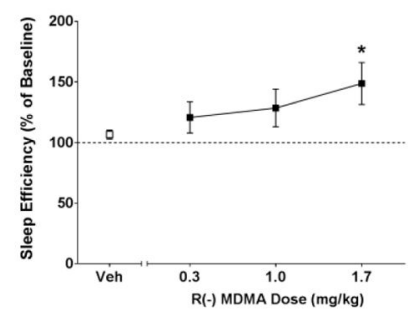

E

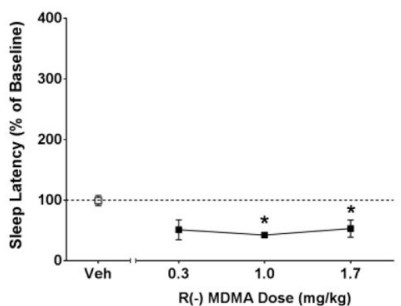

$\mathbf{F}$

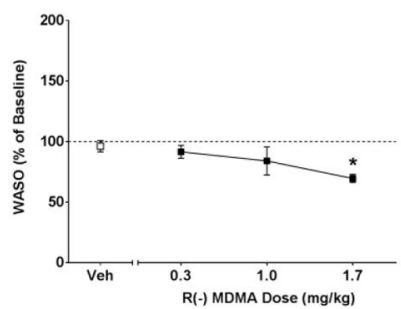

Figure 2.

(A,D) Sleep efficiency, (B,E) sleep latency and (C,F) wake time after sleep onset (WASO) in the nights after afternoon (16h) vehicle (Veh), racemic MDMA (0.3, 1.0 and $1.7 \mathrm{mg} / \mathrm{kg}$, i.m., upper panel) or R(-) MDMA (0.3, 1.0 and $1.7 \mathrm{mg} / \mathrm{kg}$, i.m., bottom panel) administrations ( $\mathrm{N}$ $=6$ ). Sleep-like measures are presented as normalized data (percentage of baseline). Data are expressed as mean \pm SEM. Dotted lines represent baseline sleep parameters $(100 \%)$. ${ }^{*}<<0.05$ compared with vehicle.

Exp Clin Psychopharmacol. Author manuscript; available in PMC 2019 August 01. 
Racemic MDMA Afternoon Treatments
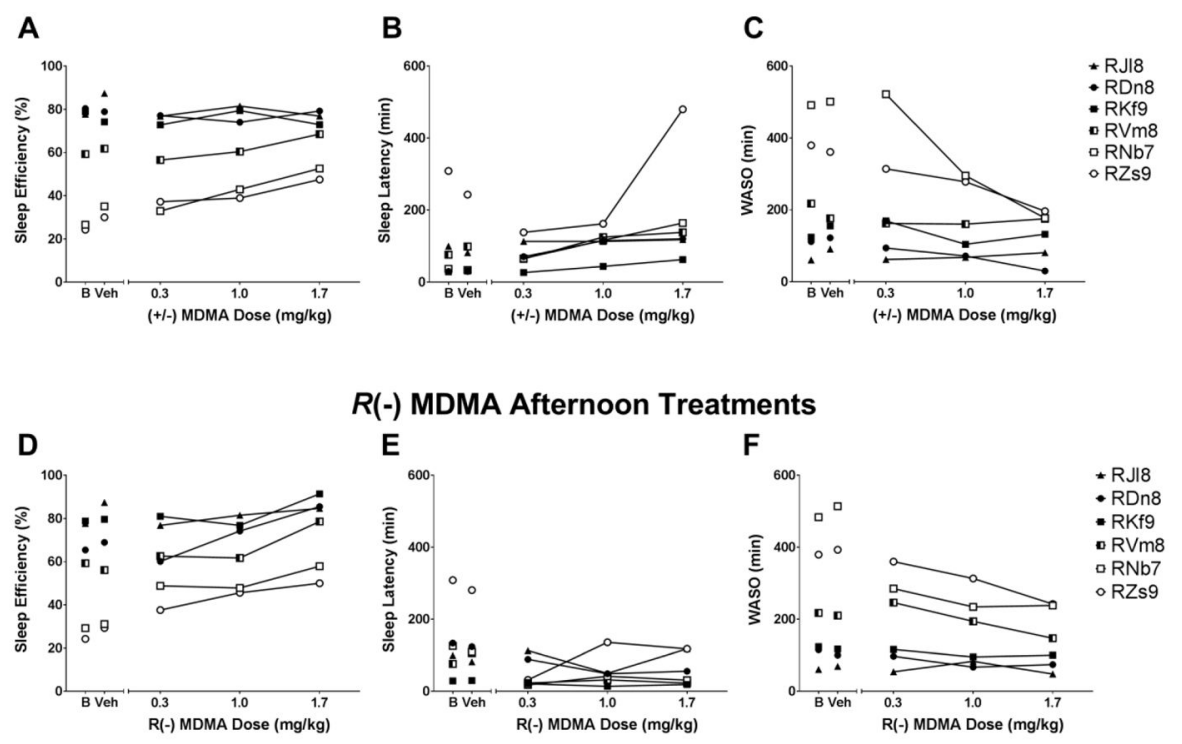

\section{Figure 3.}

Individual subject sleep parameters on baseline (B) and in the nights after afternoon (16h) treatments with vehicle (Veh) or (A, sleep efficiency; B, sleep latency; C, wake time after sleep onset - WASO) racemic MDMA (0.3, 1.0 and $1.7 \mathrm{mg} / \mathrm{kg}$, i.m.) or (D, sleep efficiency; E, sleep latency; F, WASO) $R(-)$ MDMA $(0.3,1.0$ and $1.7 \mathrm{mg} / \mathrm{kg}$, i.m. $)(\mathrm{N}=6)$. 
A

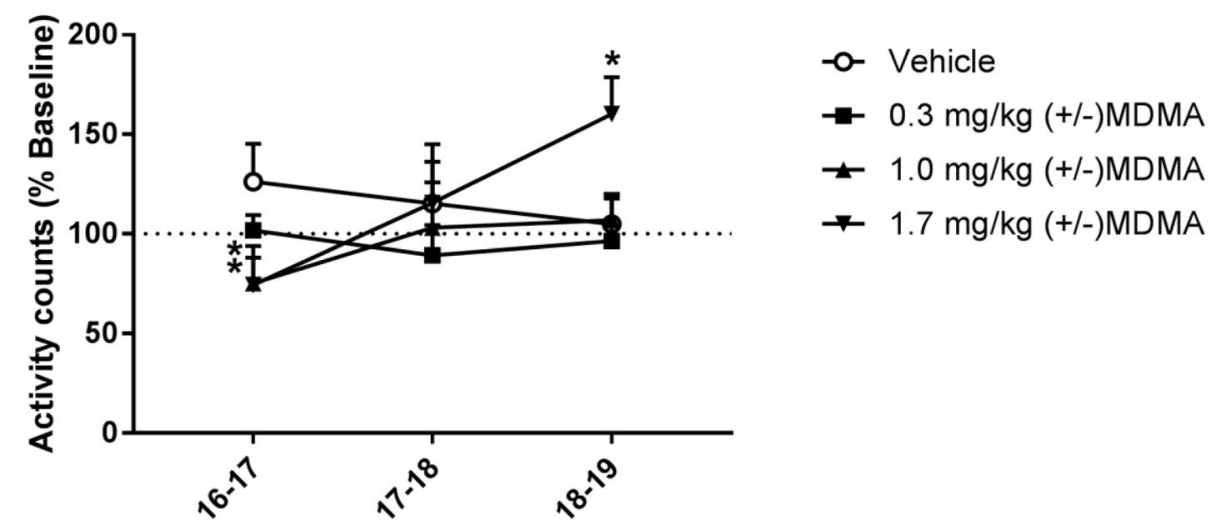

Hour

B

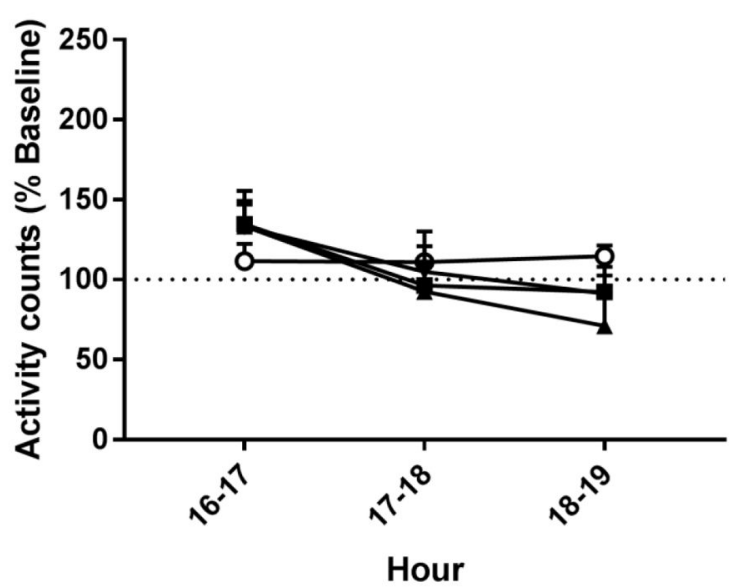

- - Vehicle
$-0.3 \mathrm{mg} / \mathrm{kg} \mathrm{R}(-) M D M A$
$\leftarrow 1.0 \mathrm{mg} / \mathrm{kg} \mathrm{R}(-) M D M A$
$\rightarrow 1.7 \mathrm{mg} / \mathrm{kg} \mathrm{R}(-) M D M A$

Figure 4.

General home-cage daytime activity in the hours after vehicle, (A) racemic MDMA (0.3, 1.0 and $1.7 \mathrm{mg} / \mathrm{kg}$, i.m.) or (B) $R(-)$ MDMA $(0.3,1.0$ and $1.7 \mathrm{mg} / \mathrm{kg}$, i.m.) afternoon (16h) administrations $(\mathrm{N}=6)$. Daytime activity measures are presented as normalized data (percentage of baseline). Data are expressed as mean \pm SEM. Dotted lines represent baseline daytime activity $(100 \%)$. ${ }^{*} \mathrm{p}<0.05$ compared with vehicle.

Exp Clin Psychopharmacol. Author manuscript; available in PMC 2019 August 01. 


\section{Table 1}

Individual-subject baseline daytime activity and sleep-like parameters

\begin{tabular}{|c|c|c|c|c|}
\hline Subject & Sleep Efficiency $(\%)$ & Sleep Latency (min) & WASO (min) & Daytime Activity (activity counts/hour) \\
\hline RDn8 (F) & $80.38 \pm 1.45$ & $29.75 \pm 9.23$ & $111.50 \pm 15.01$ & $11406 \pm 940$ \\
\hline RKf9 (F) & $78.80 \pm 1.70$ & $29.07 \pm 7.30$ & $123.69 \pm 11.34$ & $22675 \pm 1226$ \\
\hline RNb7 (F) & $26.57 \pm 19.13$ & $119.92 \pm 74.49$ & $491.50 \pm 150.38$ & $15125 \pm 652$ \\
\hline RVm8 (F) & $59.26 \pm 8.52$ & $76.2 \pm 64.53$ & $217.2 \pm 37.18$ & $10944 \pm 303$ \\
\hline RZs9 (F) & $24.24 \pm 2.71$ & $240.33 \pm 52.79$ & $379.54 \pm 97.55$ & $14606 \pm 552$ \\
\hline RJ18 (M) & $86.05 \pm 3.68$ & $33 \pm 29.41$ & $77.50 \pm 10.71$ & $14630 \pm 505$ \\
\hline
\end{tabular}

$\mathrm{F}=$ female rhesus monkey; $\mathrm{M}=$ male rhesus monkey; $\mathrm{WASO}=$ wake time after sleep onset. Data are expressed as mean $\pm \mathrm{SD}$. 